Allen P. Britton, University of Michigan

\title{
Founding JRME: A Personal View
}

You can find all the most pertinent facts concerning the founding of the Journal of Research in Music Education in Fred A. Warren's doctoral dissertation. Chapter 5, reprinted as part of this month's Forum, deals specifically with JRME and quotes extensively from the original proposals and MENC executive board actions. Warren presents the main story very fully, and I recommend it to you for the facts of the matter. What Warren couldn't do, or wouldn't try to do in a doctoral dissertation, was to describe my more personal experiences while trying to get the MENC to sponsor a new journal that might somehow get into conflict with the Music Educators Journal, then, as now, our financial bread and butter.

It wasn't easy, but it wasn't too hard either, and I want to tell you just how we did it. In 1951, I was a fairly new assistant professor of music education at the University of Michigan. Since getting my job in $1949 \mathrm{I}$ had been working in the development of the doctoral program. Frankly, I had the notion of developing a program in music education that would equal in quality the program in musicology, already well established. I realized very soon that the lack of a professional journal of national and international influence would probably preclude the publication of the research reports that would derive from our program at Michigan as well as from other developing programs at Columbia, Eastman, Illinois, Indiana, and elsewhere. Other scholarly journals at the time were little interested in music education. Journals of education were little interested in music, or in any specific subject matter.

So, with this in mind I sought out my colleague, and the great star of our department, Marguerite Hood, then president of MENC, and we talked over the possibility of getting out something from right here in Ann Arbor-we at first envisioned a kind of mimeographed newsletter. Then, one day in the spring of 1951, Warren S. Freeman, then dean of the school of music at Boston University, came to town to consult with Marguerite regarding various MENC matters. I happened to be in Burton Tower at the time, where Marguerite had her office, and we all got into a general conversation. Warren startled us by declaring his opinion that MENC should begin publication of a research journal as soon as possible.

It struck us all that the time was ripe, that positive action should now be taken. It was agreed that Warren and I would prepare a proposal in 
the form of an article for $M E J$. As I recall, Freeman was too busy himself to do the writing, so the burden fell on me, and we submitted the result to $M E J$ as coauthors.

Busy in the planning of the 1952 national meeting to be held in Philadelphia, Marguerite was in day-by-day communication with Clifford Buttelman and Vanett Lawler, the executive secretary and assistant executive secretary (as we used to designate these officers) respectively of MENC. Well, as Marguerite soon found out, the proposal was anything but welcome in Chicago. Cliff and Vanett already had a journal on their hands- $M E J$ - they certainly could not find time for another; and, besides, they felt that very few members of MENC were interested in research. As a matter of fact, they were even then contemplating doing away with the summaries of master's theses that William S. Larson had been editing for $M E J$ as a regular feature.

Nevertheless, Marguerite persisted, and she scheduled an open meeting on the subject for the national convention. For this she secured the official sponsorship of the Research Council, William R. Sur, chairman; the Editorial Board, Robert A. Choate, chairman; the Committee on Music in Higher Education, Earl E. Beach, chairman; and its Subcommittee on Graduate Study, Theodore F. Normann, chairman. Impressive as this was, Marguerite discovered, when galley proofs of the program booklet arrived, that notice of the meeting had been deleted in the national office. Marguerite put it back only to find it missing from the page proofs. You can believe that it got back again, since Marguerite was not easily put off when fully resolved.

The meeting was well attended, and the general idea was unanimously approved. Marguerite appointed an ad hoc committee to draft a new proposal incorporating ideas that were brought up in the discussion: Theodore F. Normann, chairman, Will Larson, Harold Spivacke, and myself. In anticipation of our yet-to-be-written report, Ted and I were authorized to meet immediately with the MENC executive board to brief them on our plans and to secure from them any suggestions they might offer. In those days, the executive board met at midnight, as soon as the hallowed lobby sing concluded. Ted and I waited in an adjacent room until about 1:30 a.m. before we were called in to present our case. We were well received but, of course, given no immediate answer. The report of the ad hoc committee was submitted in May, and at its meeting of May 30,1952, the board adopted it in principle and authorized the publication of two trial issues.

Another consideration must now be mentioned, if truth is to be fully observed. Ralph E. Rush of the University of Southern California had arranged an appointment with me during the conference in connection with a position open in music education at his school. He offered me the job, and in the course of our conversation I mentioned the hopes some of us had of establishing a research journal. Would I have time to devote to it if I came to USC? Ralph assured me of his interest and support. Quite by coincidence, he was soon thereafter (i.e., within a day or two) nominated and elected to succeed Marguerite as president of MENC. In those remote and simpler times, nominations and elections were all 
accomplished at the national meeting itself. No one could have any idea when he arrived that he might leave as president. Everything depended upon who happened to get asked in the lobby to serve on the nominating committee. Who could predict who might be standing in the lobby when the officer in charge of appointing the committee came through?

What with both Marguerite and Ralph supporting the proposal, and on the basis of the solemn pledge made by Ted and I that the new journal would be self-sufficient financially, we were given the go ahead. In a letter dated September 11, 1952, Ralph, as the new president, appointed the editorial committee and editorial associates set forth on the masthead of Volume 1, Number 1, dated Spring 1953. That issue is before me now, and as I gaze at the names of each dear friend my mind is flooded with pleasant memories. I am extremely grateful for the opportunity given me to work with committee members William S. Larson, Thurber H. Madison, Theodore F. Normann, Harold Spivacke, and Joseph J. Weigand, and associates Earl Beach, Bjornar Bergethon, William R. Fisher, Neal E. Glenn, Roderick D. Gordon, Wiley L. Housewright, Warner Imig, Charles Leonhard, Lilla Belle Pitts, Hartley D. Snyder, Everett Timm, and Himie Voxman. Excepting only those who have preceded us in death, we are all still friends. At this distance of time, I wonder how we assembled this wonderful bunch. Just luck, I guess.

I immediately sent the following letter to all concerned:

September 18, 1952

TO MEMBERS OF THE EDITORIAL COMMITTEE AND ASSOCIATE EDITORS, JOURNAL OF RESEARCH IN MUSIC EDUCATION

Gentlemen and Ladies:

It is a source of great satisfaction to me that you have accepted an editorial appointment to the staff of the JOURNAL OF RESEARCH IN MUSIC EDUCATION. Ralph Rush has told me that in his opinion the establishment of this publication is the most important single project of the present biennium. All of us now have a great responsibility and opportunity for rendering a difficult but vital service to our profession.

The following materials have been enclosed for your information:

\section{THE MLA STYLE SHEET}

2. A copy of the original proposal [i.e., that of the ad hoc committee] for establishing the journal.

3. Directions for contributors and publishers.

4. Recommended style for typescripts. 
Mimeographed copies of items 3 and 4 have been prepared by the national office and may be secured upon request, or you may make your own copies.

THE MLA STYLE SHEET has been adopted by practically every scholarly journal published in the United States. I suggest that we adopt it also, making such modifications as may be necessary for printing articles of a scientific nature. [Please note this flexibility.]

The original proposal for establishing a research journal was adopted in principle by the Executive Committee of MENC. It will provide the general basis upon which we will proceed. At least four modifications have already been made, however:

1. The term "Editorial Board" has been changed to "Editorial Committee" in order to avoid confusion with the Editorial Board of the MUSIC EDUCATORS JOURNAL.

2. Initial publication will not be as a periodical. Issues will appear as suitable materials are submitted. I think we will all agree that periodical publication should be instituted as soon as possible. [It was instituted immediately.]

3. The proposed size of 32 pages was predicated upon periodical publication. It may be possible to publish larger issues singly. [First was 80 pages.]

4. Refer to the original report, page 3, section $\mathrm{E}$, items 2,3 , and 4 . The national office will take care of all business details. Clifford Buttelman and Vanett Lawler will serve as managing editor and assistant managing editor respectively.

Now, as to the status of the project at the present time.-Acceptances of editorial appointments are still coming in. A complete list will be sent when possible.-Theodore F. Normann has written an article concerning JRME which will be published in a forthcoming issue of the MUSIC EDUCATORS JOURNAL.

Letters have been sent out requesting articles from all those who have written doctoral dissertations in music education during the past few years-all whose names and addresses could be found, that is. Undoubtedly, many people were inadvertently missed, especially recent graduates. No invidious distinctions were intended, of course, and I shall appreciate receiving suggestions from you as to possible contributors.-Seven scholars have already written in offering to supply articles in the near future.Letters of information have also been sent to all schools offering graduate work in music education.

I hope that you will study all of the enclosed materials closely, as they embody statements of proposed working plans and editorial policies. As editors, it is now your responsibility to make suggestions regarding anything having to do with the new publication. The initial planning which goes into a project of this kind can determine its success or failure, and all of us must put our best efforts into the matter. 
Once more, let me express my appreciation of your cooperation. Send me any ideas that occur to you and be on the lookout for contributions.

Cordially yours,

Allen P. Britton

School of Music

University of Michigan

Ann Arbor, Michigan

You see that we continued to change our ideas as we went along. For all their initial reservations, we got enormous help from Cliff and Vanett. As soon as I could, I took the train to Chicago, where Cliff taught me all about 12-point type, Old Style No. 7, how to read type upside down and backwards, and similar printer's lore. The first number was printed in Chicago by the Kable Company, then the printer of $M E J$. However, the job was put out for bidding, and to my surprise and delight, we got our low bid from Craft Press of Ann Arbor, right across the street from my office in the old building on Maynard Street. For several years I simply carried the edited copy across the street, where the typesetter, who was also one of the proprietors, would set up the hot lead while I watched. Not everything was so easy. For one thing, Craft Press did not stock mailing envelopes large enough to allow for the wide margins I envisioned, for JRME was intended insofar as possible to resemble in format the Journal of the American Musicological Society. We had to cut down the pages to fit the envelopes. This reduced the width of the margins, so we did not achieve the elegance of JAMS. Furthermore, Craft Press was unable to acquire the type face used then and now in $J A M S$. That elegant face with its long ascenders and descenders belongs exclusively to the William Byrd Press of Virginia. We settled on Old Style No. 7, the nearest likeness. On the whole, nevertheless, JRME looked beautiful to me when I was handed the first copy to come from the binder.

I had designed the logo myself, utilizing the four shape notes discussed in the article by Irving Lowens and me that appeared in the first number: "The Easy Instructor (1798-1831): A History and Bibliography of the First Shape Note Tune Book" (Figure 1). This logo was retained when the cover was first redesigned in 1966 (Figure 2). However, an entirely new cover was designed in 1972, and the logo suffered a severe distortion (Figure 3). Although the shape notes were there, above the issue date, they no longer were positioned in the rational ascending sequence demanded by the shapes themselves. The cover was changed in Spring of 1981; modernized shapes still appear on the cover, but in their irrational form (Figure 4). Each shape, as you may know, represents a degree of the diatonic scale according to the old foursyllable solmization, which renders the major scale as fa-sol-la-fa-sol-la-mi$f a$. The original design had them say sol-la-mi-fa (equivalent to C-D-E-F 


\section{Journal of Research in Music Education}

A Publication of the Music Educators National Conference

Volume I SPRING 1953 NUMBER 1

$$
\text { לddpt }
$$

TABLE OF CONTENTS

Band Programs in Minnesota.

By PAUL S. Ivory

The Study of Music at the University of Oxford in the Middle Ages (to 1450 . cation to Music Education, the College Basic Music Course, and Critic Teaching.

By VioLA A. Bzody

The Eary Instructor (1798-1831): A History and Bibliography of the Fir

By Izving Lowens and ALLen P. Britron [31]

Administrative Policies for the College and University Band.

The Determination of Musical Experionces Designed to Develop Musical Competencies Required of Elementary School Teachers in Maryland.

The History of the Flute and Its Music in the United States.

By Paul H. Grzoux

Reviews.

By John Bryden, NeAL E. GLenN, WiLgy L. Housewracht, Warner Imig, Thurger h. Madison, Hartley D. SNyder, Susan WatT, and
J. J. Wetgand

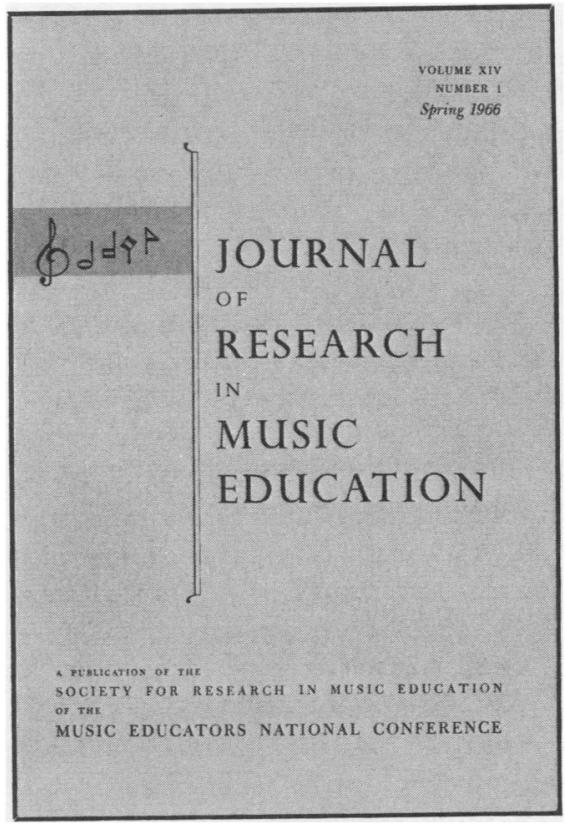

Figure 1. Title Page, JRME, I(1), Showing Original Logo
Figure 2. JRME Cover Style Adopted with Volume 14 

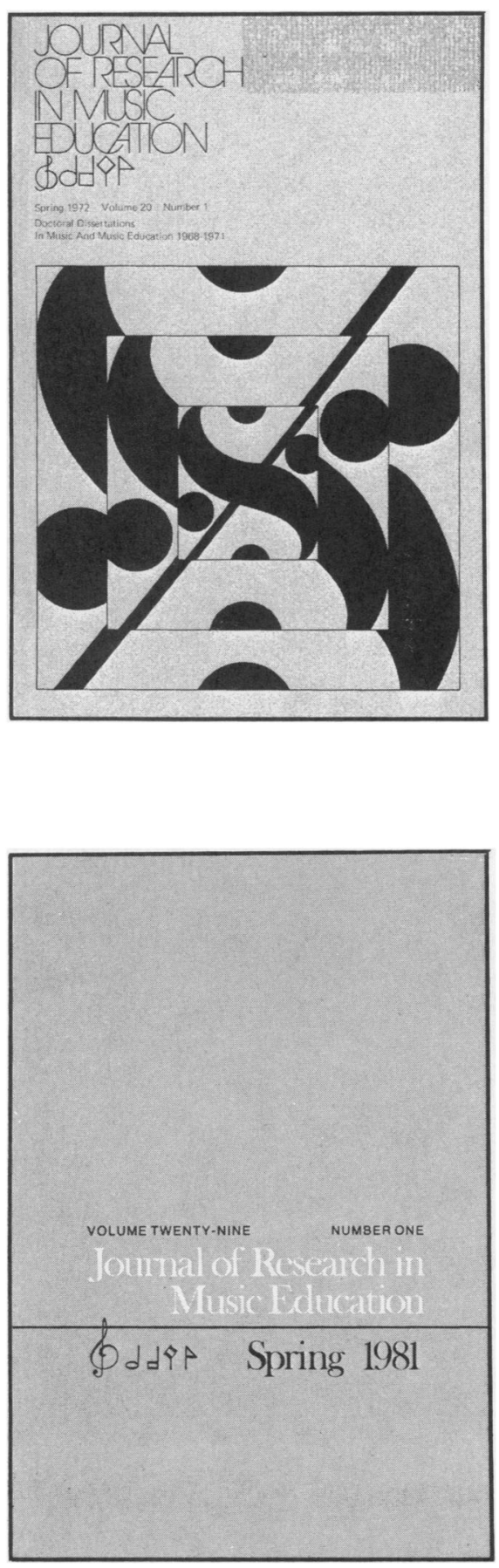

Figure 3. JRME Cover Style Adopted with Volume 20
Figure 4. JRME Cover Style Adopted with Volume 29 
and G-A-B-C), thus defining the tetrachord basic to the musical theory not only of Ancient Greece but also of 17th- and 18th-century Britain and British America. The shapes are strictly an invention of early American music education. The arrangement now appearing equates sol with $l a$, and $m e$ with $f a$, certainly a disturbing sight to all devotees of the genuine fasola.

Logos are one thing. Editorial content and style are something else. I resigned as editor in 1972, not because my logo had been distorted, but because 20 volumes seemed enough for one man to prepare, and my new duties as dean of music at Michigan precluded my giving JRME the attention it deserved. My name last appeared on the masthead in the Summer issue of 1972, Volume 20, Number 2. Robert G. Petzold, a member of the editorial committee, succeeded to the editorship. For some time thereafter, of course, the articles that appeared in JRME had been selected while I was still editor, and Bob continued in his instructions to contributors the use of my original phrase, "The editors welcome contributions of a philosophical, historical, or scientific nature that report the results of research pertinent in any way to instructions in music. ... [M]anuscript style should follow recommendations made in the MLA Style Sheet." Bob also continued my citation practice of allowing authors to use either footnotes or an endlist of references, that is, either the "humanistic" style followed by JAMS and other historical journals or the "scientific" style followed by educational and psychological journals.

Since music education as a profession includes both humanists and scientists, or is presumed to do so, JRME originally provided a forum for all, leaving authors free to choose the style of citation most congenial to them. During Bob's editorship, however, the interests of our profession, as expressed in the submitted research reports, tended toward the experimental rather than the historical. By the time James C. Carlsen became editor (Fall issue of 1978, Volume 26, Number 3) very few historical articles were to be had, it would seem. With the Spring issue of 1979 , Volume 27, Number 1, a significant change in the instructions was approved by the Editorial Committee. The "instructions to contributors" page read: "The Journal of Research in Music Education publishes reports of research of a theoretical, historical, or systematic nature that clearly make a contribution to a theory of music education. . . . Manuscript style must conform to the Publication Manual of the American Psychological Association." George Duerksen took over as interim chairman of the editorial committee with the Winter issue of 1981, Volume 29, Number 4 , abandoning the title editor. I doubt that the change had any significance with regard to how JRME was actually run; I had the same title (i.e., chairman) myself from 1953 until 1956, when I was designated editor. I do not remember why this came about, for sure, but I think it had something to do with indicating that JRME was edited by a regular member of MENC rather than by a paid employee in the national office. $M E J$, as you know, has always been edited there.

During Duerksen's tenure, the Editorial Committee approved another change in the wording of the instructions to contributors so as to read: $J R M E$ "publishes reports of research that clearly make a contribution to 
theories of music education." The required style was not changed, however, so that $J R M E$ still looks more like something put out by the American Psychological Association than by the American Musicological Society. Why favor one over the other? Why not allow each author to choose one style or the other? Here we continue, it seems to me, the old and senseless feud between humanists and scientists, between the subject-matter specialist and the professional educator. In so doing we exacerbate the wound we should be trying to heal. I take this seriously. Music education as a profession continues to suffer to the extent that musicians think us mediocre musicians and that professional educators think us too little concerned with social values. It seems to me that our constant duty is to demonstrate that musical and social values are in fact interdependent. We should avoid the appearance as well as the act of supporting one camp at the expense of the other, regardless of personal predilection.

And now, before concluding this reminiscence, let me assure Jack Taylor, who took over in the Fall of 1982, Volume 30, Number 3, that he enjoys my full and sympathetic support, even though he continues to use the changed instructions and citation style. As the former chairman of countless committees, I possess, I believe, as good an idea as anyone as to how much individuality a chairman can get away with. Let me also refer you for a more extended discussion of these matters to the article by George N. Heller and Bruce D. Wilson, "Historical Research in Music Education: A Prolegomenon," Bulletin of the Council for Research in Music Education 60, (Winter 1982), pages 1-20. My own viewpoint coincides with theirs in most particulars, of course, but it also includes other impressions, hard to express and easy to misinterpret. Let me conclude with them.

In helping to establish $J R M E$ and in continuing to serve as its editor for 20 years, I must confess that one of my fondest hopes saw music education brought closer to music itself, to the performers and composers engaged in its creation, and also brought closer to musical scholarship, to the musicologists and music critics who prepare the articles, books, encyclopedias, and the like that give literary expression to musical art. It was my feeling then as now that as a profession we were too much inclined to tag along the pathways of professional education, pathways that to my mind seemed to be leading nowhere, that tended to trail out as professional education constantly struck out on new paths, continually deserting the old as a kind of determined policy. I felt that the contemplation of our history might give some sense of worth and purpose to a people wandering in an intellectual wilderness, so to speak. In a word, I sought to glorify the junior high school bandmaster, together with the high school choral director, the elementary school general music teacher, and all the other earnest musicians working in what I considered the Lord's vineyards, and to help all music teachers as a group sense this glory by giving them the dignity of historical place.

At the same time, I never thought to deny the possibility that experimental research might somehow turn up something of value, even though no "theory of music education" exists in any scientific sense, nor 
is one likely to come into existence until long after the secrets of the atom have been fully revealed, together with the mysteries of the hemispheres of the brain.

Was the effort successful? Was the effort worth the while? Of course it was, but not completely so. Shall we say that it did not fail entirely? The situation is brighter from this standpoint, I believe, than it was 30-odd years ago. For my own part, I am pleased with what was done and with what continues to be done. I side with those who believe that the effort itself is what counts, providing only that it seeks the greatest good for mankind, the most beautiful in music, the most kindness in teaching, the most truth in scholarship. Or something like that.

If only the logo made more sense. 